\title{
Gas chromatography-mass spectrometry analysis of volatile compounds from Houttuynia cordata Thunb after extraction by solid-phase microextraction, flash evaporation and steam distillation
}

\author{
Minmin Liang, ${ }^{\mathrm{a}, *}$, Meiling $\mathrm{Qi}^{\mathrm{a}}$, Changbin Zhang ${ }^{\mathrm{b}}$, Shan Zhou ${ }^{\mathrm{c}}$, Ruonong Fu ${ }^{\mathrm{a}}$, Junxiong Huang ${ }^{\mathrm{b}}$ \\ a Department of Chemistry, School of Chemical Engineering and Materials Science, Beijing Institute of Technology, Beijing 100081, PR China \\ ${ }^{\mathrm{b}}$ Research Center for Eco-Environmental Sciences, Chinese Academy of Sciences, Beijing 100085, PR China \\ ${ }^{\mathrm{c}}$ Beijing Municipal Center for Disease Prevention and Control, Beijing 100020, PR China
}

Received 28 August 2004; received in revised form 29 September 2004; accepted 29 September 2004

Available online 22 January 2005

\begin{abstract}
Various sampling techniques including flash evaporation (FE), headspace solid-phase microextraction (HS-SPME) and steam distillation (SD) were compared for the gas chromatography-mass spectrometry of volatile constituents present in Houttuynia cordata Thunb (HCT). 2-Undecanone $(22.21 \%)$ and houttuynum (7.23\%) were predominant components of HCT samples obtained by HS-SPME whereas those levels were 3.95 and $3.60 \%$ in the same samples by FE and 25.93 and $6.60 \%$ in those by SD, respectively. SPME with polydimethylsiloxane (PDMS) fibre was more selective and particularly efficient for the isolation of biologically active compounds and afforded a higher yield of total compounds than FE and SD. A total of 60 compounds were detected in SPME extracts. While in FE and SD extracts, the detected compounds were 41 and 51, respectively. The total amount of compounds isolated by SPME was much larger than that isolated by FE or SD. Some minor constituents were isolated by SPME, but not by SD and FE. This carries great significance because of the importance of the oil volatiles to clinical therapy. HS-SPME is a powerful tool for determining the volatile constitutes present in the TCMs.
\end{abstract}

(C) 2004 Elsevier B.V. All rights reserved.

Keywords: Headspace solid-phase microextraction; Flash evaporation; Stream distillation; Volatile compounds; Houttuynia cordata Thunb

\section{Introduction}

Historically, especially in Asian areas, traditional Chinese medicines (TCMs) have played an important role in clinical therapy. Because of their high pharmacological activity, low toxicity and rare complication [1], more and more interests have been re-attracted in recent years. However, TCMs contain large amount of proteins, sugars, mucilage and tannin in addition to their volatile components, which makes the isolation and measurement of the volatile constituents as well as quality control of crude drugs and their medical preparations extremely difficult. Traditionally, the analysis of volatile compounds from TCMs is usually pre-

\footnotetext{
* Corresponding author. Tel.: +86 1068941647.

E-mail addresses: minml@sina.com, minmlzcb@hotmail.com (M. Liang).
}

ceded by the extraction of essential oil by steam distillation, which often requires a large amount of sample and takes several hours to complete. The complex and time-consuming process for the preparation of samples sometimes further complicates the analytical results due to more influencing factors involved. Solid-phase microextraction (SPME) developed by Pawliszyn and coworkers in 1989, is a solventless extraction technique widely used in application of extraction from plants, food, biological and environmental samples [2-6]. SPME has diminished decomposition of plant compounds and cells, minimized activity of enzyme, and decreasing loss of those constituents. SPME techniques offer a useful alternative to conventional techniques. Flash evaporation gas chromatography (FE-GC) is also a rapid way of analyzing volatile compounds in TCMs. The analytical process of FE-GC involves the volatilization of the volatile components in the plant powder in a heater (a PYR-4A pyrolyzer 
was used in this study) and the entrance into the GC column for the following chromatographic separation. With this method, the ground powder of a TCM material can be directly applied for the analysis and no extraction is required. Furthermore, the amount of sample used is greatly reduced and only a few milligrams of the ground powder of a TCM material are needed, which greatly simplify and shorten the analytical process for volatile compounds from TCMs. FE-GC is of great significance for the rapid identification and quality control of TCMs. The simplicity and the high sensitivity of the two procedures render them the desirable techniques for the analysis of volatile compounds in HCT.

Houttuynia cordata Thunb has been a time-honored traditional Chinese medicine (TCM). It provides a wide range of pharmacological activities including antiviral $[7,8]$, antileukemic [9], antioxidative and antimutagenic effects $[10,11]$. Medicinal properties claimed for the drug have been attributed to its volatile oil $[12,13]$. A main component in the essential oil of this medicinal plant, decanoyl acetadehyde, is known to be of pharmacological effects, but it is unstable and easily oxidized (shown in Fig. 1) $[14,15]$ in the process of distillation and during storage. It is often required that the essential oil of this plant should be freshly prepared before analysis and sometimes some stabilizing reagent should be added, which leads to the inconvenience of the analysis. This problem can be addressed perfectly by SPME-GC and FEGC because they need no solvent extraction. In addition, as this plant exhibits an ample range of biological activity and is widely used in folk medicine, it is very important to extend the study to other volatile constituents present in this TCM.

Some publications are available concerning the essential oil composition of H. cordata Thunb by GC-MS [12-17], in which the essential oils were extracted by steam distillation and identified by GC-MS, and 34 compounds from wild $H$. cordata Thunb [16] and 42 compounds from cultivated $H$. cordata Thunb [17] were identified. However, little has been reported concerning the volatile compounds from $H$. cordata Thunb after extraction by solid-phase microextraction and flash evaporation [12-17].

In the present study, we compared three different extraction techniques including HS-SPME, FE and SD for GC-MS of volatile constituents from HCT. The temperature and the particle size of the ground powder of the plant for the FE process and the absorption time, temperature, headspace volume for the HS-PDMS process were optimized. Compounds ex- tracted from HCT were identified according to mass spectra and by comparison with standard substances.

\section{Experimental}

\subsection{Material}

Samples of wild HCT were obtained commercially from Jiangxi Province, China. Prior to use, samples were air dried, ground in a high-speed rotary cutting mill, and then screened to give fractions $250,150,125$ and $75 \mu \mathrm{m}$ in size.

\subsection{Extraction}

\subsubsection{Steam distillation extraction}

The essential oil was prepared as follows: $100 \mathrm{~g}$ sample of $125 \mu \mathrm{m}$ particle size was weighted into a $2000 \mathrm{~mL}$ distillation flask, $1000 \mathrm{~mL}$ deionised water was added and the mixture was distilled for $4 \mathrm{~h}$. Oil was collected from the condenser and $0.2 \mathrm{~mL}$ of oil was diluted with $5 \mathrm{~mL}$ of $n$-hexane. Then the extracts were dried with anhydrous sodium sulfate. The particle size of the plant powder is important for steam distillation. In order to compare with FE results, the same particle size of $125 \mu \mathrm{m}$ was used for steam distillation.

\subsubsection{HS-SPME extraction}

The manual SPME holder was used with a $100 \mu \mathrm{m}$ polydimethylsiloxane fibre assembly (Supelco, Bellefonte, USA). Before use, the fibre was conditioned as recommended by the manufacturer. The extraction experiments were carried out in two series. The first was to determine the effect of the absorption temperature and time on extraction efficiency. First, the sample $(2.0 \mathrm{~g})$ of $125 \mu \mathrm{m}$ particle size was hermetically sealed in an $8 \mathrm{~mL}$ vial, then SPME fibre was suspended in the HS and equilibrated for nine different time ranges of $5,10,15,20,25,30,40,50$ and $60 \mathrm{~min}$ in a thermostatic bath, which was set at the temperature of either $40,50,60$, 80 or $100^{\circ} \mathrm{C}$. Only that part of the vial with the solid matrix was submerged, to keep the SPME fibre as cool as possible to improve the vapour phase/absorbent fibre coating partition coefficient [18]. The second group of experiments was performed to establish the effect of headspace volume on extraction efficiency. These experiments were performed using $2 \mathrm{~g}$ of sample in different size vials, with a headspace volume

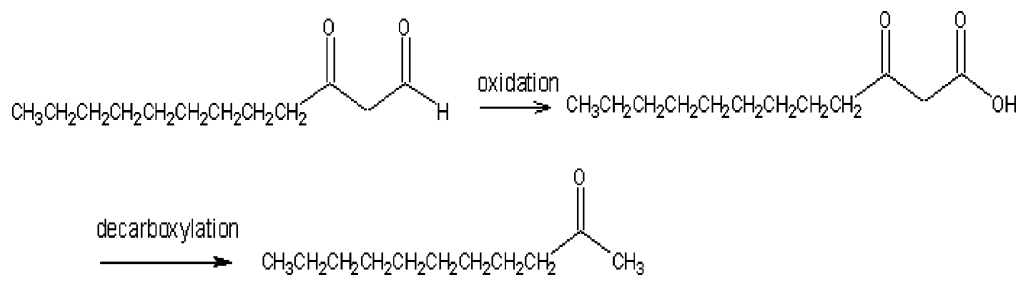

Fig. 1. The houttuynum (decanoyl acetaldehyde) may be converted into 2-undecanone via both oxidation and decarboxylation. 
of $4,8,15,22$ and $40 \mathrm{~mL}$. Based on the results of the first group of experiments, the second series were conducted at $80^{\circ} \mathrm{C}$ for $20 \mathrm{~min}$.

\subsubsection{Flash evaporation extraction}

The FE was conducted in a PYR-4A pyrolyzer (Shimazhu, Japan). The pyrolyzer was directly attached to a gas chromatograph. The extraction experiments were carried out in two series too. The first was to determine the effect of the flash evaporation temperature on extraction efficiency. When the pyrolyzer reached the selected temperature of either 150 , $200,250,300,350$ or $700^{\circ} \mathrm{C}$ under a sweeping gas, the sample of $125 \mu \mathrm{m}$ particle size was fed by a screw feeder. In order to avoid release of the volatiles in the sample prior to the pyrolyzer, the feeding system was cooled by water. The second group of experiments was performed to establish the effect of particle size on the extraction efficiency. These experiments were conducted using four different particle size ranges $\left(D_{\mathrm{p}}\right)$, namely $250,150,125$ and $75 \mu \mathrm{m}$. Based on the results of the first group of experiments, the evaporation temperature of the second series was kept at $250^{\circ} \mathrm{C}$.

\subsection{Gas chromatography-mass spectrometry}

GC-MS analyses were carried out by using a HewlettPackard (HP) (Palo Alto, CA, USA) 5890A Series II gas chromatograph with electron impact ionization mode. A DB$5 \mathrm{MS}$ column $(30 \mathrm{~m} \times 0.25 \mathrm{~mm} \times 0.25 \mu \mathrm{m}, \mathrm{J} . \& \mathrm{~W}$. Scientific, USA) was used with an oven program of $80-240{ }^{\circ} \mathrm{C}$ at $3{ }^{\circ} \mathrm{C} / \mathrm{min}$ for the first $20 \mathrm{~min}$ and $1{ }^{\circ} \mathrm{C} / \mathrm{min}$ for the rest time. The final temperature was held for $10 \mathrm{~min}$. The injector temperature was $240^{\circ} \mathrm{C}$. The flow-rate of the carrier gas (He, $99.9995 \%$ ) was $1.0 \mathrm{~mL} / \mathrm{min}$. A split injection with a ratio of 1:30 was used. The sample volume injected was $2 \mathrm{~mL}$. The mass spectrometer was fitted with an EI source operated $70 \mathrm{eV}$ with a source temperature of $180^{\circ} \mathrm{C}$, and mass spectra were recorded in the range $\mathrm{m} / \mathrm{z}, 50-400 \mathrm{amu}$ in the full-scan acquisition mode. Volatile compounds were identified by comparing the obtained mass spectra of the relevant chromatographic peaks with those of authentic standards and with spectra of the NIST and Wiley libraries.

For the optimization of FE conditions a GC-14B gas chromatograph with FID (Shimadzu, Kyoto, Japan) was also used. Injector and detector temperatures were set at 240 and $260^{\circ} \mathrm{C}$, respectively. Gas flow-rates were kept as follows: nitrogen carrier gas, $1 \mathrm{~mL} / \mathrm{min}$; hydrogen, $35 \mathrm{~mL} / \mathrm{min}$; air, $500 \mathrm{~mL} / \mathrm{min}$. The other conditions were the same as those of the GC-MS.

\section{Results and discussion}

\subsection{Optimization of HS-SPME conditions}

SPME, unlike most conventional sampling techniques, is not based on an exhaustive extraction of the sample, but on equilibrium between the analyte concentration in the sample or sample headspace and that in the solid-phase fibre coating. The extraction temperature and time were investigated. The experiments were carried out at $40,50,60,80$ and $100^{\circ} \mathrm{C}$ with extraction times from 5 to $60 \mathrm{~min}$. The results are shown in Fig. 2. As can be seen, there was an obvious increase in the response when the temperature was increased from 40 to $60^{\circ} \mathrm{C}$. As extraction temperature increased from 60 to $80^{\circ} \mathrm{C}$ the response showed another obvious increase. When the temperature was further increased to $100^{\circ} \mathrm{C}$, no significant increase in the response was observed. An increase in extraction temperature causes an increase in extraction rate, and simultaneously a decrease in the distribution constant. Therefore, an adequate temperature, which provides satisfactory sensitivity and extraction rate should be used. In this case, $80^{\circ} \mathrm{C}$ was determined to be sufficient for extracting the essential oil in sample.

The time required to reach the equilibrium is the optimal sampling time. The results in Fig. 2 show that the equilibrium was reached after $20 \mathrm{~min}$ when the extraction temperature was set at $80^{\circ} \mathrm{C}$. Further exposure up to $60 \mathrm{~min}$ did not show any increase in the response. When the extraction temperature was $40,50,60,80$ and $100^{\circ} \mathrm{C}$, the equilibrium was reached after $40,30,25,20$ and $15 \mathrm{~min}$, respectively. The results indicate that the equilibration time progressively decreases with increasing temperature. For subsequent studies, the extraction time was set at $20 \mathrm{~min}$ for $80^{\circ} \mathrm{C}$.

The effect of the headspace volume on extraction efficiency was investigated next. A set of experiments were performed using $2 \mathrm{~g}$ of sample in different size vials, with a headspace volume of $4,8,15,22$ and $40 \mathrm{~mL}$. The results obtained for eight major oil constituents are showed in Fig. 3. The responses obtained were similar for headspace volumes between 4 and $22 \mathrm{~mL}$. The ability to work with bigger HS volume without obviously decreasing the response of the method has an important practical advantage, because the fibre can be situated in bigger size container, such, there is a lesser tendency for sample particles to stick on the fibre, which results in a cleaner operation. For a headspace volume

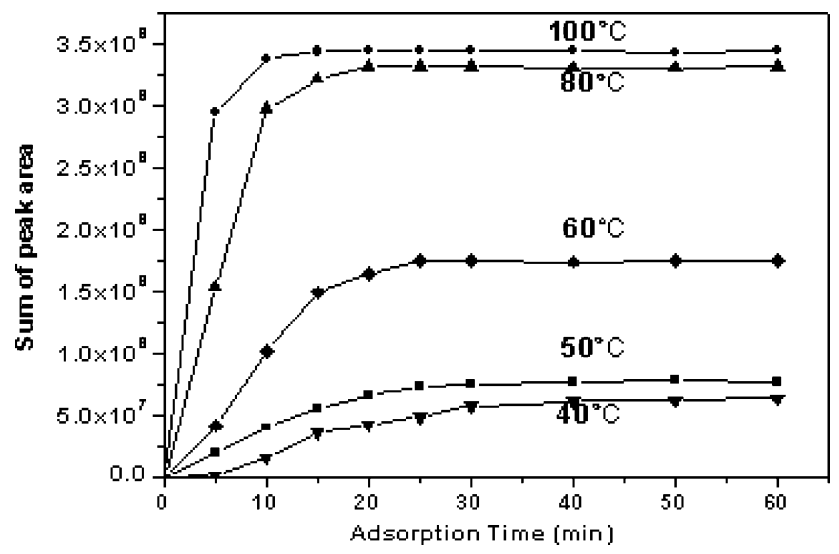

Fig. 2. Effect of absorption time and temperature on the sum of the peak areas of the volatile compounds of H. cordata Thunb by HS-SPME. 


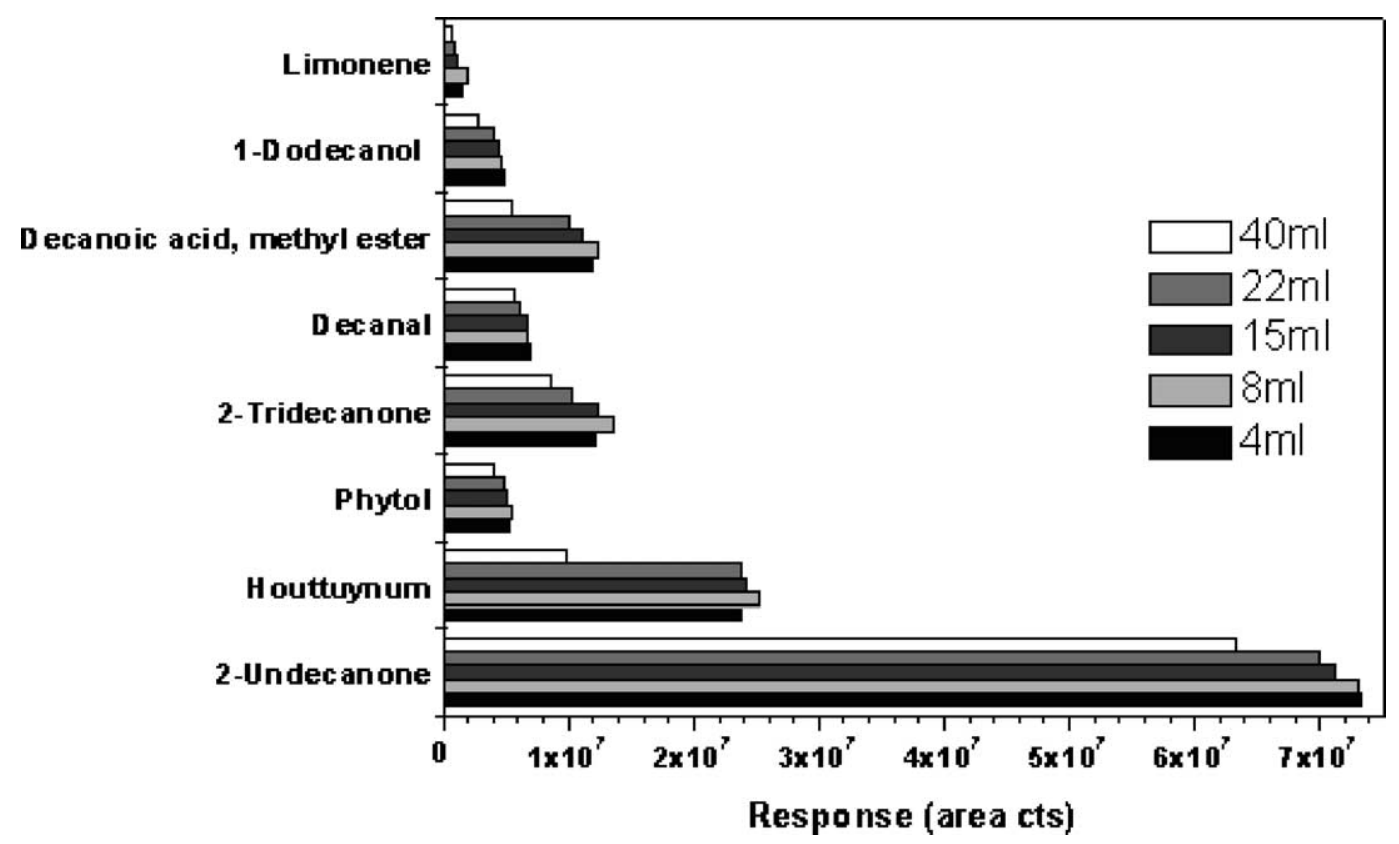

Fig. 3. Effect of headspace volume on the response of main volatile components from H. cordata Thunb by HS-SPME.

of approximately $40 \mathrm{~mL}$ the response was lower, between 57 and $86 \%$ of the response obtained with the other four headspace volumes.

\subsection{Optimization of FE conditions}

For a FE-GC analysis, the flash evaporation temperature is a key factor and should be optimized to find the right one offering the maximum volatilization of the volatile components in the powder sample while avoiding the occurrence of pyrolysis and thus keeping the volatilized components intact.

To obtain the right flash evaporation temperature, the effects of temperature on the extraction efficiency were studied. Fig. 4 shows the responses for five major oil constituents

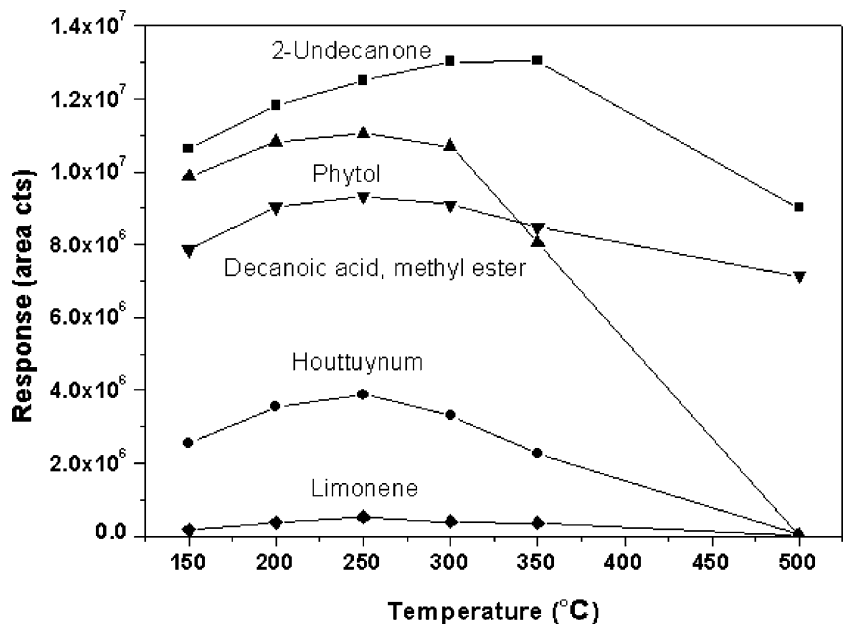

Fig. 4. Effect of flash evaporation temperatures on the response of main volatile components from $H$. cordata Thunb by FE. in relation to final FE temperatures at 150, 200, 250, 300, 350 and $500{ }^{\circ} \mathrm{C}$ for the particles of $125 \mu \mathrm{m}$ size. As can be seen, there was an increase in the response in all cases, when the final evaporation temperature was increased from 150 to $250^{\circ} \mathrm{C}$. 2-Undecanone showed continual increasing trend and phytol, decanoic acid methyl ester, houttuyum, limonene decreased as the temperature was further increased from 250 to $350^{\circ} \mathrm{C}$. At the lowest evaporation temperature, $150^{\circ} \mathrm{C}$, the responses were low in all cases. It indicates that the temperature should be improved to promote the release of volatiles. As the temperature increased to $250^{\circ} \mathrm{C}$, the amount of phytol, houttuynum and limonene increased to their maximum responses. At a higher temperature, $350{ }^{\circ} \mathrm{C}$ or more, the responses decreased. The response of decanoic acid methyl ester was nearly constant in the range $8.4 \times 10^{6}-9.3 \times 10^{6}$ over the temperature range of $150-500{ }^{\circ} \mathrm{C}$. In general, the response increased to an optimum value with higher temperature and then decreased. It may be concluded that oxidation of the volatiles and further decomposition proceeded in the reactor with increasing temperature. If these results are investigated with respect to maximum volatiles responses, it is clear that the optimum evaporation temperature is $250^{\circ} \mathrm{C}$ under the experimental conditions used. Therefore, in the later experiments, the evaporation temperature was held at $250^{\circ} \mathrm{C}$.

The particle size of the plant powder was another factor affecting FE-GC analysis. Different particle sizes of the plant powder (250-75 $\mu \mathrm{m}$, the inner diameter of the mesh pore) were prepared and used for FE-GC analyses under the described conditions. It was found that both the peak number and the static effect increased with the decrease of the particle size. As a result of a compromise between the peak number and the static effect, the particle size of $125 \mu \mathrm{m}$ was finally used for this study. These results suggest that the particle size 


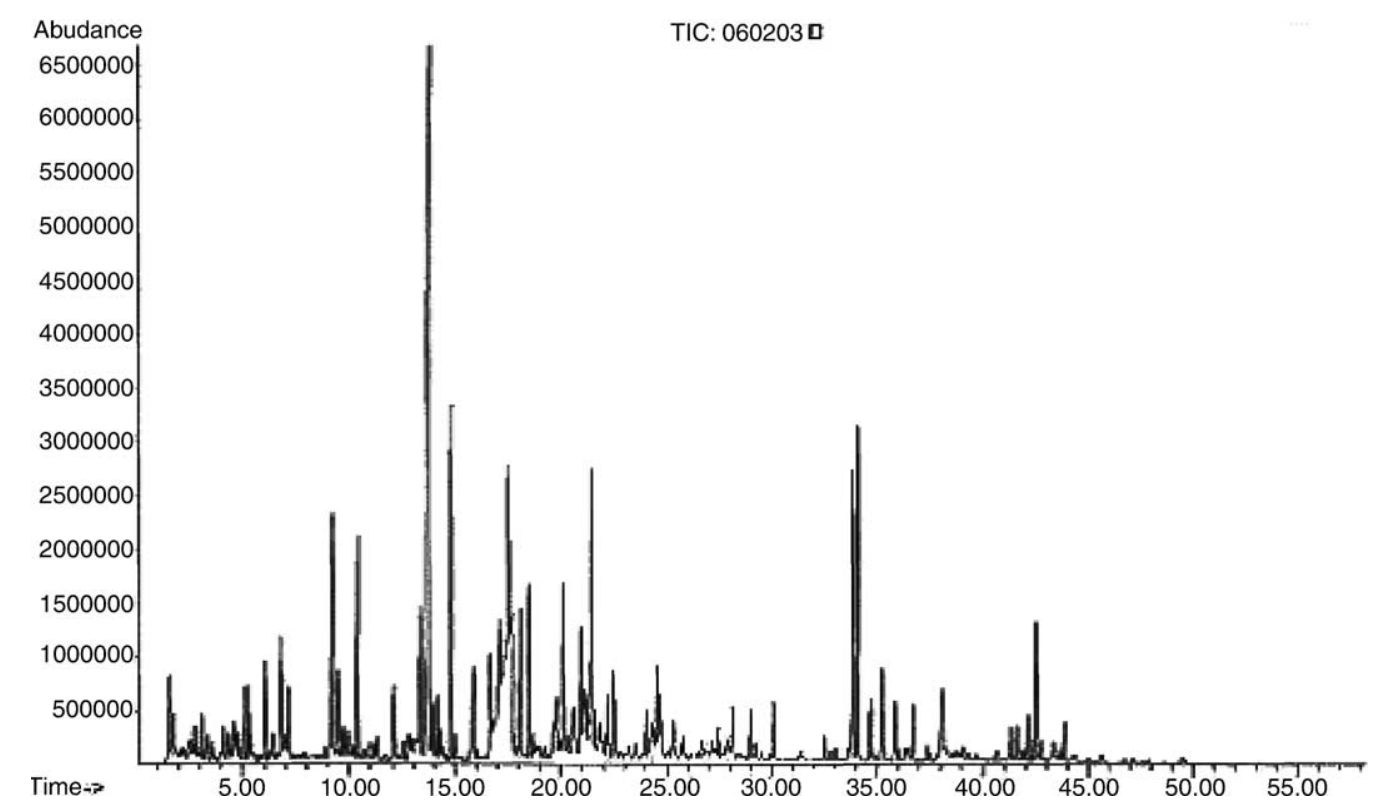

Fig. 5. Typical chromatograms of volatile components of $H$. cordata Thunb by HS-SPME under the extraction condition of $80^{\circ} \mathrm{C}$ and $20 \mathrm{~min}$.

is very important for the escape of the volatile compounds from the inside of the particle.

\subsection{Determination of the identified analytes}

The analysis was performed under the analytical conditions indicated above directly. Fig. 5 illustrates GC-MS chromatograms resulting from the SPME sampling. Table 1 shows the components and their relative proportions (\% total ion current). They were identified as mostly 2 -undecanone, houttuynum, aliphatic acid and aliphatic aldehydes, i.e. houttuynum is indicated as responsible for the characteristic smell of HCT [4]. Seventy-two compounds were identified. Though the number of components was high, two most significant compounds, 2-undecanone and houttuynum, were dominant. These two compounds are of much interest since they often relate to biological activity. By SPME-GC-MS, resolved mass spectra of the main compounds (a) 2-undecanone, $\mathrm{Mr} 170, \mathrm{M}^{+}(-),[\mathrm{M}-\mathrm{CH} 3]^{+} \mathrm{m} / \mathrm{z}$ 155, [M- $\left.\mathrm{CH}_{3} \mathrm{CO}\right]^{+} \mathrm{m} / \mathrm{z} 127, \mathrm{CH}_{3} \mathrm{CO}^{+} \mathrm{m} / \mathrm{z}, 43, \mathrm{CH}_{3}(\mathrm{CH} 2)_{4}{ }^{+}$ $\mathrm{m} / \mathrm{z}$ 71, and rearrangement fragments $\mathrm{CH}_{3} \mathrm{COHCH}_{2}{ }^{+} \mathrm{m} / z, 58$, (b) houttuynum, $\mathrm{Mr} 198, \mathrm{M}^{+}(-),[\mathrm{M}-\mathrm{CH} 3]^{+} \mathrm{m} / z, 183$, [M$\mathrm{CHO}^{+} \mathrm{m} / \mathrm{z}$ 169, [M-CH$\left.{ }_{2} \mathrm{CO}\right]^{+} \mathrm{m} / \mathrm{z} 155$, [M-COCH$\left.{ }_{2} \mathrm{COH}\right]^{+}$ $\mathrm{m} / z$ 127, $\mathrm{HCOCH}_{2} \mathrm{CO}^{+} \mathrm{m} / \mathrm{z} 71$ and rearrangement fragments $\mathrm{CH}_{3} \mathrm{COHCH}_{2}{ }^{+} \mathrm{m} / \mathrm{z}$ 58, are shown in Fig. 6. Other compounds, in small but significant proportions were phytol, 2-tridecanone, decanal, decanoic acid methyl ester, 1undecanol, limonene, cycloheptane and dicyclobutylidene oxide.

\subsection{Comparison of three extraction methods, $H S$-SPME, FE and $S D$}

A comparison of the compositions of HS-SPME extracts, FE extracts and SD extracts is presented in Table 1. As can be seen, more volatile compounds were extracted and identified by SPME method than by SD and FE method. A total of 60 compounds were detected in SPME extracts. While in FE and SD extracts, the detected compounds were 41 and 51, respectively. The total amount of compounds isolated by SPME was much larger than that isolated by FE or SD. Some minor constituents were isolated by SPME, but not by SD and FE. This carries great significance because of the importance of the oil volatiles to clinical therapy. It may be concluded that oils extracted by SPME were less prone to thermal degradation than SD and FE for the low isolation temperature. Two principal compounds, houttuynum and 2-undecanone, were detected at concentrations of 7.23 and $22.21 \%$ in the SPME extracts, of $3.60,3.59 \%$ in FE extracts, and 6.60, 25.93\% in SD extracts. The concentration of houttuynum was higher than that in SD and FE. It may be due to the simply, short and solventless extraction process and the relatively low isolation temperature, which efficiently inhibited oxidation and decarboxylation of houttuynum. The fact that the SPME method can greatly increase the response of houttuynum has a significant practical advantage for its biological activity. The results of this study indicate that SPME was both selective and highly efficient in the isolation of biologically active compounds present in HCT. In addition, the results are comparable to those given by SD.

In SD extracts, 51 compounds were identified. A variety of SPME detected compounds were not detected by $\mathrm{SD}$, revealing the limit of the SD method. It may not promote certain species and mask the detection of less abundant components.

FE extracts were rich $(>60 \%)$ in oxygenated compounds such as aliphatic acid (acetic acid 5.03\%, linoleic acid 3.60\%, octadecanoic acid $0.66 \%, n$-hexadecanoic acid $4.94 \%$ ), 
Table 1

Chemical composition of $H$. cordata Thunb extracts obtained by HS-SPME, FE and SD

\begin{tabular}{|c|c|c|c|c|c|}
\hline No & Retention time (min) & Compound & HS-SPME \% RA & FE \% RA & $\mathrm{SD} \% \mathrm{RA}$ \\
\hline 1 & 1.54 & Acetic acid & 1.43 & 5.03 & 0.26 \\
\hline 2 & 2.47 & 4-Pyridinamine & 0.15 & - & - \\
\hline 3 & 2.53 & Furfural & 0.13 & - & $<0.1$ \\
\hline 4 & 2.67 & 2-Furanmethanol & 0.35 & - & 0.10 \\
\hline 5 & 3.36 & Pyrazine, ethyl- & 0.24 & - & - \\
\hline 6 & 4.28 & Dimethyl trisulfide & 0.31 & 1.32 & 0.14 \\
\hline 7 & 4.55 & 2-Fuanmethanol, acetate & 0.54 & 1.77 & - \\
\hline 8 & 4.85 & Alpha-Phellandrene & 0.26 & - & $<0.1$ \\
\hline 9 & 5.10 & Cyclohexene, 1-methyl- & 0.59 & - & - \\
\hline 10 & 5.67 & Limonene & 0.65 & 0.87 & 0.40 \\
\hline 11 & 6.62 & Borneol & 0.26 & - & 0.10 \\
\hline 12 & 8.87 & 5-Octadecene, (E)- & $<0.1$ & 0.84 & 0.27 \\
\hline 13 & 9.21 & 1-Nonanol & 3.27 & 2.18 & 2.70 \\
\hline 14 & 9.93 & 2-Decanone & 0.22 & 1.14 & 0.21 \\
\hline 15 & 10.40 & Decanal & 2.05 & 0.60 & 4.51 \\
\hline 16 & 11.82 & 2-Furancarboxalder, 5-(hydroxymethyl)- & $<0.1$ & 3.46 & - \\
\hline 17 & 12.26 & 2-Undecene, 9-methyl-, (E)- & $<0.1$ & - & 3.23 \\
\hline 18 & 12.94 & Benzamide & - & - & 0.41 \\
\hline 19 & 13.81 & 2-Undecanone & 22.21 & 3.95 & 25.93 \\
\hline 20 & 13.86 & 1-Decen-3-one & - & 3.68 & 0.73 \\
\hline 21 & 13.93 & 2-Undecanol & 0.53 & - & 0.40 \\
\hline 22 & 14.14 & Undecanal & 0.50 & - & 0.49 \\
\hline 23 & 14.28 & Acetic acid, decyl ester & 0.28 & 0.45 & 0.27 \\
\hline 24 & 14.80 & Decanoic acid, methyl ester & 3.73 & 1.37 & 1.35 \\
\hline 25 & 16.64 & 1-Dodecanol & 1.39 & 1.07 & 1.34 \\
\hline 26 & 17.52 & 2-Dodecanone & 1.73 & - & 0.96 \\
\hline 27 & 18.06 & Dodecanal & 1.55 & - & - \\
\hline 28 & 18.48 & Caryophyllene & 1.79 & - & 2.56 \\
\hline 29 & 18.66 & Undecanoic acid, methyl ester & 0.21 & 0.76 & $<0.1$ \\
\hline 30 & 19.34 & Nonadecanoic acid, ethyl ester & - & 0.36 & - \\
\hline 31 & 19.50 & 2-Tridecanone & 3.60 & 4.27 & 5.61 \\
\hline 32 & 19.66 & Cycloisolongifolene, 8,9-dehydro- & 0.51 & - & - \\
\hline 33 & 20.12 & $\begin{array}{l}\text { 1H-Cycloprop[e]azulene,1a,2,3,4,4a,5,6,7b-octahydro-1,1,4,7-tetramethyl-, } \\
\text { [1ar-(1a.alpha.,4.beta.,4a.beta.,7.alpha.,7a.beta.,7b.alpha.)] }\end{array}$ & 2.03 & 1.78 & 1.07 \\
\hline 34 & 20.93 & 2-Isopropenyl-4a,8-dimethyl-1,2,3,4,4a,5,6,7-octahydronaphthalene & 1.50 & - & 0.96 \\
\hline 35 & 21.36 & Tetracyclo[6.3.2.0(2,5).0(1,8)]tridecan-9-ol,4,4-dimethyl- & 0.27 & - & 0.23 \\
\hline 36 & 21.04 & Eudesma-4(14),11-diene & 1.13 & - & 0.42 \\
\hline 37 & 21.47 & Houttuynum & 7.23 & 3.60 & 6.60 \\
\hline 38 & 22.01 & Isoaromadendrene epoxide & $<0.1$ & 1.74 & $<0.1$ \\
\hline 39 & 22.23 & (-)-.alpha.-Panasinsen & 0.73 & - & 0.57 \\
\hline 40 & 22.47 & $\begin{array}{l}\text { Naphthalene,1,2,3,4-tetramethyl-4-(1-methylethyl)-, } \\
\text { (1.alpha.,4a.alpha.,8a.alpha.)- }\end{array}$ & 2.39 & 0.81 & 0.96 \\
\hline 41 & 22.89 & cis-Z- $\alpha$-Bisabolene epoxide & 0.47 & 0.48 & 0.24 \\
\hline 42 & 23.19 & Quinoline, 5,8-dimethyl- & 0.23 & - & - \\
\hline 43 & 23.83 & 2-Pentadecanone & $<0.1$ & - & 0.17 \\
\hline 44 & 24.01 & 1,6,10-Dodecatriene, 7,11-dimethyl-3-methylene-,(E)- & 0.49 & 0.91 & 0.47 \\
\hline 45 & 24.51 & Spathulenol & 1.19 & - & 0.86 \\
\hline 46 & 24.70 & Caryophyllene oxide & 1.15 & 2.70 & 1.97 \\
\hline 47 & 25.24 & Oxirane, tettadecyl- & 1.09 & 4.30 & 1.27 \\
\hline 48 & 25.80 & Tetradecanal & 0.23 & - & 0.14 \\
\hline 49 & 27.61 & Butyl-2-methylpropylphthalate & $<0.1$ & 1.74 & - \\
\hline 50 & 30.18 & 3,7,11,15-Tetramethyl-2-hexadecen-1-ol & $<0.1$ & 3.68 & 0.73 \\
\hline 51 & 31.38 & Anthracene & 0.12 & - & 0.16 \\
\hline 52 & 33.84 & 1-Hexadecyne & 3.55 & - & $<0.1$ \\
\hline 53 & 34.06 & 2-Pentadecanone,6,10,14-trimethyl- & 3.95 & - & 2.71 \\
\hline 54 & 35.23 & 1-Dodecyne & 1.10 & - & - \\
\hline 55 & 38.10 & $n$-Hexadecanoic acid & 2.58 & 4.94 & 3.35 \\
\hline 56 & 38.50 & Cyclohexadecane & 0.40 & - & 0.20 \\
\hline 57 & 38.71 & 9,12-octadecadienoic acid (Z,Z)- & - & 0.43 & 0.99 \\
\hline 58 & 38.95 & Linoleic acid & $<0.1$ & 3.60 & 0.74 \\
\hline 59 & 39.03 & Heptadecane & 0.52 & 0.24 & 0.17 \\
\hline
\end{tabular}


Table 1

Chemical composition of $H$. cordata Thunb extracts obtained by HS-SPME, FE and SD

\begin{tabular}{|c|c|c|c|c|c|}
\hline No & Retention time (min) & Compound & HS-SPME \% RA & FE \% RA & $\mathrm{SD} \% \mathrm{RA}$ \\
\hline 60 & 41.33 & 10-Nonadecanone & 0.34 & - & - \\
\hline 61 & 42.50 & Phytol & 1.65 & 3.95 & 1.49 \\
\hline 62 & 42.89 & Octadecanoic acid & - & 0.66 & - \\
\hline 63 & 43.27 & 13-octadecenal,(z)- & - & 0.65 & - \\
\hline 64 & 43.96 & Octadecane & - & 0.96 & - \\
\hline 65 & 44.21 & Tricosane & - & 0.49 & - \\
\hline 66 & 44.73 & Cyclohexane,(1-propylheptadecyl)- & - & 0.32 & - \\
\hline 67 & 45.24 & Hexacosane & - & 0.24 & - \\
\hline 68 & 45.81 & Octacosane & - & 0.60 & - \\
\hline 69 & 46.07 & Nonacosane & - & 0.33 & - \\
\hline 70 & 46.32 & 3,6,6-Trimethyl-cyclohex-2-enol & 0.26 & - & 0.21 \\
\hline 71 & 46.85 & 1-Hexadecene & 0.44 & $<0.1$ & - \\
\hline 72 & 47.72 & Matrine, N-oxide & - & - & $<0.1$ \\
\hline
\end{tabular}

RA: relative area (peak area relative to total peak area).
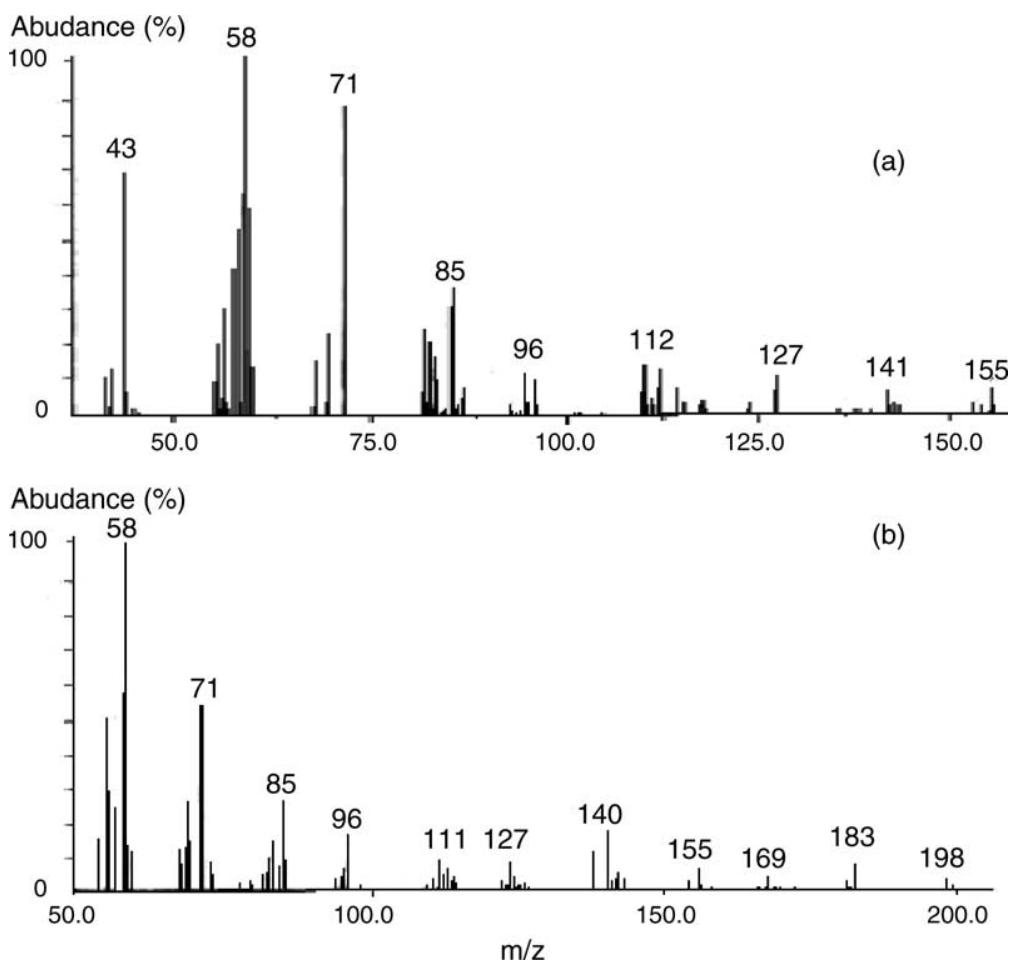

Fig. 6. Mass spectra (EI, 70 eV) from HCT sample: (a) 2-undecanone and (b) houttuynum, resolved by SPME-GC-MS.

alcohols (phytol 3.95\%, 1-nonanol 2.18\%, 1-dodecanol $1.07 \%$ ) and ketone (2-decanone 1.14\%, 2-tridecanone $4.27 \%$, 2-undecanone $3.95 \%$ ). The high concentrations of oxygenated compounds may be derived from the oxidation of essential oil, which proceeded during isolation at high evaporation temperature. In FE extracts, only 41 compounds were isolated and the most significant compounds, houttuynum and 2-undecanone, were found at relative concentrations 3.60 and $3.95 \%$ respectively, which is much lower than their SD counterparts. One possible explanation for this phenomenon was oxidation of essential oil during isolation, which may hide the componential nature of HCT. So, evaporation tem- perature is a key factor and is not easy to control. If it is high, oxidation of the components may occur. Some heavy hydrocarbons $\left(\mathrm{C}_{n}>20\right)$ such as hexacosane, tricosane, octacosane and nonacosane were observed in FE extracts, but not in SD and SPME extracts. The reason for the absence of these heavier compounds from the FE extracts is not clearly understood. However, it is known that the isolation temperature in the evaporation extraction is much higher than that in SPME and SD experiments. The high isolation temperature makes it possible to release the heavy alkanes up to $\mathrm{C}_{20}$. However, heavy compounds with active group were not detected in the extracts. It may be due to the active functionality dissociation 
early in the flash evaporation event. From the results of this study, it is found that although susceptible to some long chain aliphatics the FE method is not sensitive to many volatile compounds for the high extraction temperature, which may result in the oxidation of volatile compounds during isolation and hide the componential nature of HCT.

\section{Conclusions}

The volatile constituents of HCT were obtained by HSPDMS, FE and SD. Among those methods, HS-SPME was the most selective and particularly efficient for the isolation of volatile compounds and afforded a higher yield of total compounds than FE or SD. Also, houttuynum, the key active compound, exhibited great increase in SPME experiment for the simply, short and solventless extraction process and the relatively low isolation temperature. In SD extracts, a variety of SPME detected compounds were not detected, revealing the limit of the SD method. It may not promote certain species and mask the detection of less abundant components. FE extracts possessed a higher content of oxygenated compounds and heavier compounds for its high extraction temperature, which may result in the oxidation of volatile compounds during isolation and hide the componential nature of HCT. As a conclusion, HS-SPME is a simple, sensitive and rapid method suitable for the analysis of volatile constituents from HCT, and promising for its application to other traditional Chinese medicines. It offers a useful alternative to conventional SD technique. FE, as the poor responses of volatile compounds, is not suited for the volatile constitutes analysis.

\section{Acknowledgements}

This research work was financially supported by the key project of National Science and Technology Ministry of China (Nos. 2002DEA20021-3, 2002BA906A29).

\section{References}

[1] K.C. Wen, C.Y. Huang, F.L. Lu, J. Chromatogr. 631 (1993) 241.

[2] A. Jayatilaka, S.K. Poole, C.F. Poole, T.M.P. Chinchila, Anal. Chim. Acta 302 (1995) 147.

[3] R.P. Belardi, J. Pawliszyn, Water Pollut. Res. J. Can. 24 (1989) 179

[4] C.L. Arthur, J. Pawliszyn, Anal. Chem. 62 (1990) 2145

[5] J. Cai, B. Liu, Q. Su, J. Chromatogr. A 930 (2001) 1.

[6] C.A. Zini, H. Lprd, E. Christensen, T.F. Assis, E.B. Caramao, J. Pawliszyn, J. Chromatogr. Sci. 40 (2002) 140.

[7] L.C. Chiang, J.S. Chang, D.C. Chen, L.T. Ng, C.C. Lin, Am. J. Chin. Med. 31 (2003) 355.

[8] K. Hayashi, M.K. Amiya, T Hayashi, Planta Med. 61 (1995) 237.

[9] J.S. Chang, L.C. Chiang, C.C. Chen, L.T. Liu, K.C. Wang, C.C. Lin, Am. J. Chin. Med. 29 (2001) 303.

[10] Y.Y. Chen, J.F. Liu, C.M. Chen, P.Y. Chao, T.J. Chang, J. Nutr. Sci. Vitaminol (Tokyo) 49 (2003) 327

[11] S. Li, Q. Yu, P. Jin, J. Shenyang Pharm. Univ. 14 (1997) 144.

[12] M. Shimura, Y. Zhou, Y. Asada, Biochem. Biophys. Res. Commun. 261 (1999) 308.

[13] W.Y. Tsui, G.D. Brown, Fitoterapia 67 (1996) 479.

[14] X. Ceng, J.G. Shi, H.P. Ceng, W.L. Lai, Chin. J. Anal. Chem. 4 (2003) 399

[15] H.Y. Ceng, J.L. Jiang, J.C. Zhang, J. Plant Resour. Emrottme 12 (2003) 50

[16] X. Liu, D. Li, G. Liao, L. Wang, J. Guiyang Med. College 22 (1997) 361 .

[17] Z. Zheng, J. Shi, H. Zeng, W. Lai, Chin. J. Anal. Chem. 31 (2003) 399

[18] Z. Zhang, J. Pawliszyn, Anal. Chem. 67 (1995) 34. 